\title{
Tritium and iodine-129 concentrations in precipitation at Tsukuba, Japan, after the Fukushima Daiichi Nuclear Power Plant accident
}

\author{
TERUYUKI MARUOKa, ${ }^{1 *}$ TAKAMASA KaWAMUto, ${ }^{2}$ TAKeshi OHNO, ${ }^{2}$ YASUYUKi MURAMATSU, ${ }^{2}$ \\ Hiroyuki MATSUZAKI, ${ }^{3}$ TAKUYA MATSUMOTO ${ }^{4}$ and PRADEEP AgGARWAL ${ }^{4}$ \\ ${ }^{1}$ Faculty of Life and Environmental Sciences, University of Tsukuba, Tennodai 1-1-1, Tsukuba, Ibaraki 305-8572, Japan \\ ${ }^{2}$ Department of Chemistry, Faculty of Science, Gakushuin University, Mejiro 1-5-1, Toshima-ku, Tokyo 171-8588, Japan \\ ${ }^{3}$ Department of Nuclear Engineering and Management, School of Engineering, The University of Tokyo, \\ Yayoi 2-11-16, Bunkyo-ku, Tokyo 113-0032, Japan \\ ${ }^{4}$ Isotope Hydrology Section, International Atomic Energy Agency, Vienna, International Centre, PO Box 100, 1400 Vienna, Austria
}

(Received November 11, 2015; Accepted April 21, 2016)

\begin{abstract}
The earthquake off the Pacific coast of Japan and the subsequent tsunami on March 11, 2011, triggered a series of accidents in the Fukushima Daiichi Nuclear Power Plant (FNPP1). The accidents caused the release of a mixture of radioactive substances into the environment. This study measured the concentration of tritium $\left({ }^{3} \mathrm{H}\right)$ and iodine-129 $\left({ }^{129} \mathrm{I}\right)$ in rainwater samples collected at Tsukuba, $170 \mathrm{~km}$ southwest of the plant, during the year following the accident. High ${ }^{3} \mathrm{H}$ concentrations were observed in the rainwater samples collected within one month after the FNPP1 accident. ${ }^{3} \mathrm{H}$ concentrations decreased steadily over time and returned to the levels before the accident. Concentrations of ${ }^{129}$ I also decreased over time. However, pulses of high ${ }^{129}$ I concentrations were observed at several other times following the accident. The ${ }^{129}$ I concentrations were found to be correlated with iron concentrations in rainwater. It is likely that iron oxide, which can absorb iodate ions $\left(\mathrm{IO}_{3}{ }^{-}\right)$, was the carrier of radiogenic iodine. This study concludes that ${ }^{129} \mathrm{I}$ and also ${ }^{131} \mathrm{I}$, which is one of the most harmful radionuclides produced in nuclear reactors, can be redistributed to the atmosphere in the months following the deposition of radiogenic iodine on the ground.
\end{abstract}

Keywords: Fukushima Daiichi Nuclear Power Plant accident, volatile radionuclides, tritium, radioactive iodine, accelerator mass spectrometry

\section{INTRODUCTION}

The earthquake off the Pacific coast of Japan and the subsequent tsunami on March 11, 2011, triggered a series of accidents in the Fukushima Daiichi Nuclear Power Plant (FNPP1). Radioactive substances were subsequently released into the environment. These substances were produced in the nuclear reactors and were stored in the spent-fuel (e.g., Hirose, 2012; Steinhauser, 2014).

In light water nuclear reactors, which is the type of reactors used at FNPP $1,{ }^{3} \mathrm{H}\left(t_{1 / 2}=12.32\right.$ y; Lucas and Unterwerger, 2000) is formed from the ternary fission of nuclear fuels and from neutron activation of lithium and boron. The total amount of ${ }^{3} \mathrm{H}$ stored in FNPP1 was calculated to be $1.81 \times 10^{13} \mathrm{~Bq}$ (Schwantes et al., 2012). Matsumoto et al. (2013) reported a decrease in ${ }^{3} \mathrm{H}$ concentration in rainwater samples, with increasing distance, at sites ranging from 170 to $700 \mathrm{~km}$ from FNPP1. Based on the observed distance relationship, the atmospheric ${ }^{3} \mathrm{H}$

*Corresponding author (e-mail: maruoka.teruyuki.fu@u.tsukuba.ac.jp)

Copyright $@ 2017$ by The Geochemical Society of Japan. level at source during the early stage of the accident was estimated to be approximately $1500 \mathrm{~Bq} / \mathrm{m}^{3}$. This implies that significant amounts of ${ }^{3} \mathrm{H}$ were released from the FNPP1 and were deposited on the ground via precipitation. Measuring ${ }^{3} \mathrm{H}$ concentrations in rainwater can improve our understanding of the emission and dispersal of volatile radioactivity after a nuclear accident.

Iodine-131 $\left({ }^{131} \mathrm{I}\right)\left(t_{1 / 2}=8.0252\right.$ days; Khazov et al., 2006) is one of the most harmful radionuclides produced in nuclear reactors; therefore, the activity of ${ }^{131} \mathrm{I}$ around the accident site should be precisely evaluated to assess the impact of radioactivity on public health (e.g., Miyake et al., 2012; Doi et al., 2013). Some studies have used Iodine-129 $\left({ }^{129} \mathrm{I}\right)\left(t_{1 / 2}=1.57 \times 10^{7} \mathrm{y}\right.$; Timar et al., 2014) to estimate the distribution of ${ }^{131} \mathrm{I}$ (e.g., Muramatsu et al., 2015). ${ }^{129} \mathrm{I}$ is used because it has a longer half-life than ${ }^{131} \mathrm{I}$, which is no longer detectable after a few months.

${ }^{131} \mathrm{I}$ and ${ }^{129} \mathrm{I}$ are mobilized together, and therefore, their distribution and behavior in the environment will be similar.

In this paper, we report on measured concentrations of ${ }^{3} \mathrm{H}$ and ${ }^{129} \mathrm{I}$ from the precipitation samples collected at Tsukuba, $170 \mathrm{~km}$ southwest from the FNPP1 in the year 


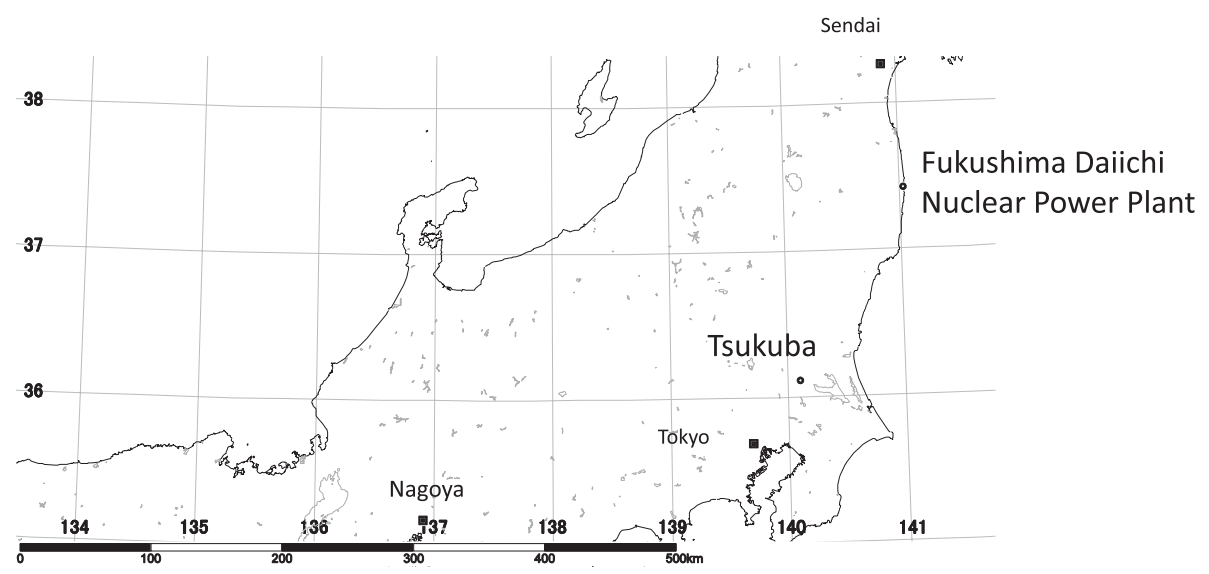

Fig. 1. Map of the sampling locality and the FNPP1.

following the accident. The purpose of this study is to improve the understanding of the behavior of these volatile radionuclides.

\section{SAMPLING AND ANALYSIS}

Rain samples were collected at University of Tsukuba, Tsukuba City, Japan, (Fig. 1) over the first year after the accident. Individual rain samples were collected in panshaped containers.

${ }^{3} \mathrm{H}$ concentrations were measured using about $500 \mathrm{ml}$ rainwater samples and the residual rainwater (if a sufficient amount of rainwater could be collected) was used for cation and ${ }^{129} \mathrm{I}$ analysis. ${ }^{3} \mathrm{H}$ analysis was carried out in the Isotope Hydrology Laboratory of the International Atomic Energy Agency (IAEA) by electrolytic enrichment followed by liquid scintillation spectrometry with a detection limit of about 0.1 TU (Gröning et al., 2009; Matsumoto et al., 2013).

Concentrations of ${ }^{129} \mathrm{I}$ were determined using accelerator mass spectrometry (AMS) at MALT (Micro Analysis Laboratory, Tandem accelerator) in the University of Tokyo (Matsuzaki et al., 2007). The standard used for the determination of ${ }^{129} \mathrm{I} /{ }^{127} \mathrm{I}$ ratios was $\mathrm{Z} 94-0596$ prepared by Prime Lab., University of Purdue. We also determined the ${ }^{129} \mathrm{I} /{ }^{127} \mathrm{I}$ ratio of the KI solution (Kanto Chemicals Co.) in order to examine the carrier blank value $\left({ }^{129} \mathrm{I} /{ }^{127} \mathrm{I}\right.$ ratio: $\left.1.8 \times 10^{-13}\right)$. About $150 \mathrm{ml}$ of rainwater was used for ${ }^{129} \mathrm{I}$ analyses of samples collected after May 2011. Smaller amounts of rainwater (1 to $40 \mathrm{ml}$ ) were used for samples collected in March and April of 2011 because these samples had higher concentrations of ${ }^{129} \mathrm{I}$.

The concentrations of cations $(\mathrm{K}, \mathrm{Na}, \mathrm{Ca}, \mathrm{Mg}, \mathrm{Al}, \mathrm{Fe}$, and $\mathrm{Mn}$ ) and ${ }^{127} \mathrm{I}$ were determined using ICP-MS/MS (Agilent 8800; Agilent Technologies, Tokyo, Japan). The analyses were conducted at Gakushuin University by comparing the results to a set of standard samples of known

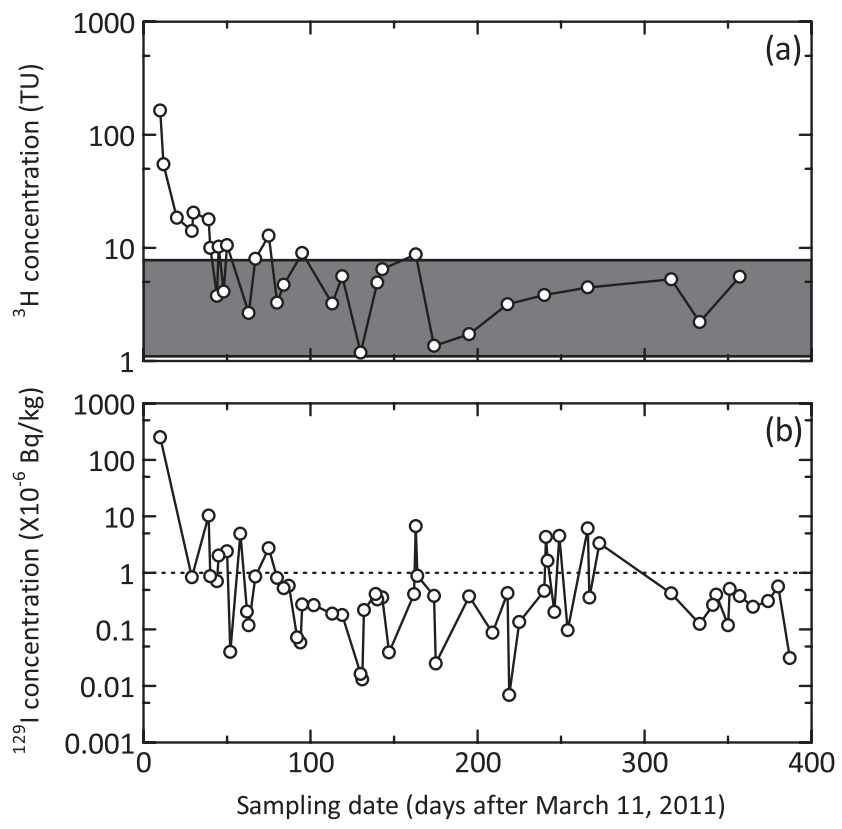

Fig. 2. Concentrations of ${ }^{3} H(a)$ and ${ }^{129} I(b)$ for individual rainfall occurences. Gray area in (a) represents pre-accident ${ }^{3} \mathrm{H}$ levels ranging from 1.1 and $7.8 \mathrm{TU}$, which were minimum and maximum ${ }^{3} \mathrm{H}$ concentrations, respectively, obtained by monthly analyses during 2001 and 2002 at Tsukuba (Yabusaki et al., 2003). Dotted line in (b) represents the threshold $\left(10^{-6}\right.$ $B q / \mathrm{kg}$ ) between high and low concentrations of ${ }^{129}$ I used in this study.

concentration. The water samples were filtered using a membrane filter with a pore size of $0.45 \mu \mathrm{m}$ before ${ }^{129} \mathrm{I}$ measurements and chemical analysis.

\section{RESULTS AND DISCUSSION}

Concentrations of ${ }^{3} \mathrm{H},{ }^{127} \mathrm{I},{ }^{129} \mathrm{I}$, cations and ${ }^{129} \mathrm{I} /{ }^{127} \mathrm{I}$ 

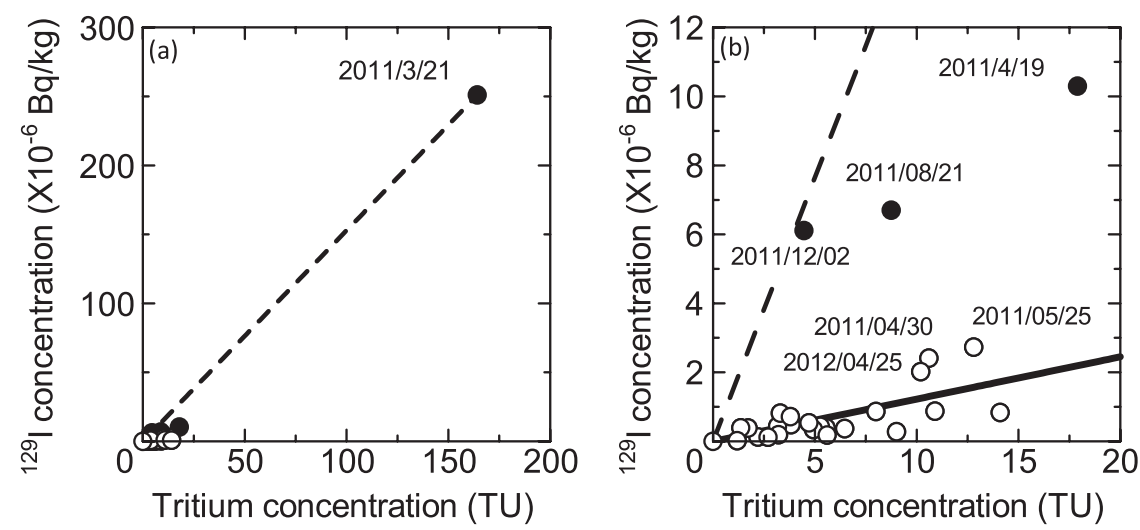

Fig. 3. Concentrations of ${ }^{129}$ I plotted against those of tritium (a), enlarged in (b). Dashed lines in (a) and (b) connect data point from March 21, 2011, to the origin. Solid line in (b) represents the regression line determined as passing the origin. The regression line were determined using data of open circle symbols $\left(R^{2}=0.48\right)$. Numbers near the data points indicate sampling dates.
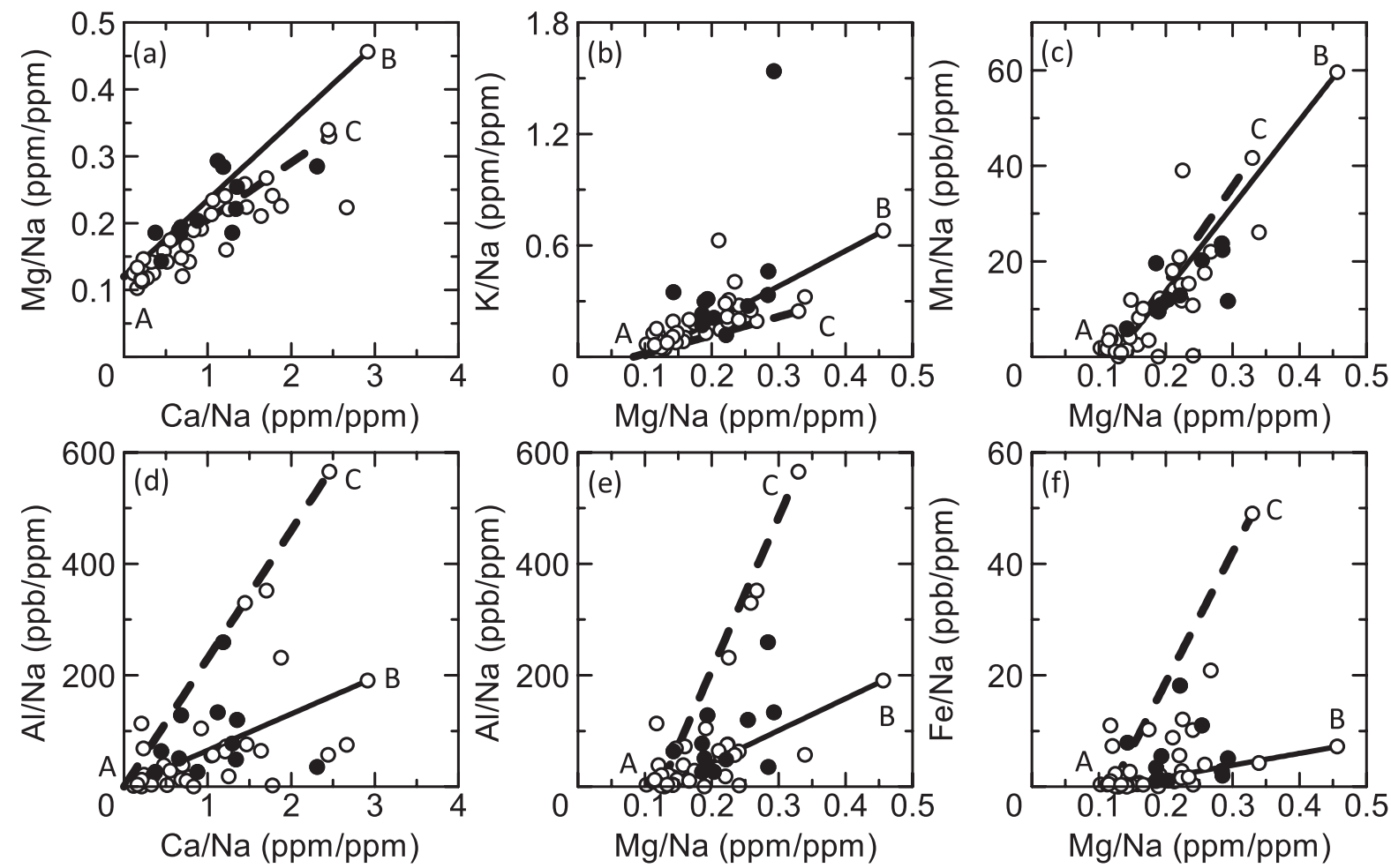

Fig. 4. Cation compositions of the rain water samples: (a) Mg/Na vs. Ca/Na (b) K/Na vs. $\mathrm{Mg} / \mathrm{Na}$ (c) $\mathrm{Mn} / \mathrm{Na}$ vs. $\mathrm{Mg} / \mathrm{Na}$ (d) Al/Na vs. Ca/Na, (e) Al/Na vs. Mg/Na, and (f) Fe/Na vs. Mg/Na. Three endmembers were proposed. Component "A" represents sea salt composition. " $B$ " and " $C$ " represent for the chemical compositions for rainwater samples collected on May 17 and 13, 2011, respectively. Solid and dashed lines connect data points of the components " $B$ " and " $C$ ", respectively, to that of component " $A$ ". Closed and open circles represent data points for samples with high $\left(>10^{-6} \mathrm{~Bq} / \mathrm{kg}\right)$ and low $\left(<10^{-6} \mathrm{~Bq} / \mathrm{kg}\right)^{129} \mathrm{I} \mathrm{concentrations,}$ respectively.

ratios from rainwater samples are given in Table 1. Higher ${ }^{3} \mathrm{H}$ concentrations were observed in the rainwater samples collected within one month after the FNPP1 accident (Fig. 2a). The ${ }^{3} \mathrm{H}$ concentrations of subsequent rainwater samples decreased steadily with time and returned to pre-accident levels (1.1-7.8 TU in Tsukuba; Yabusaki et al., 2003). This indicates that the Fukushima-derived ${ }^{3} \mathrm{H}$ was washed out from the atmosphere by precipitation within a month.

Concentrations of ${ }^{129} \mathrm{I}$ also decreased over time after 


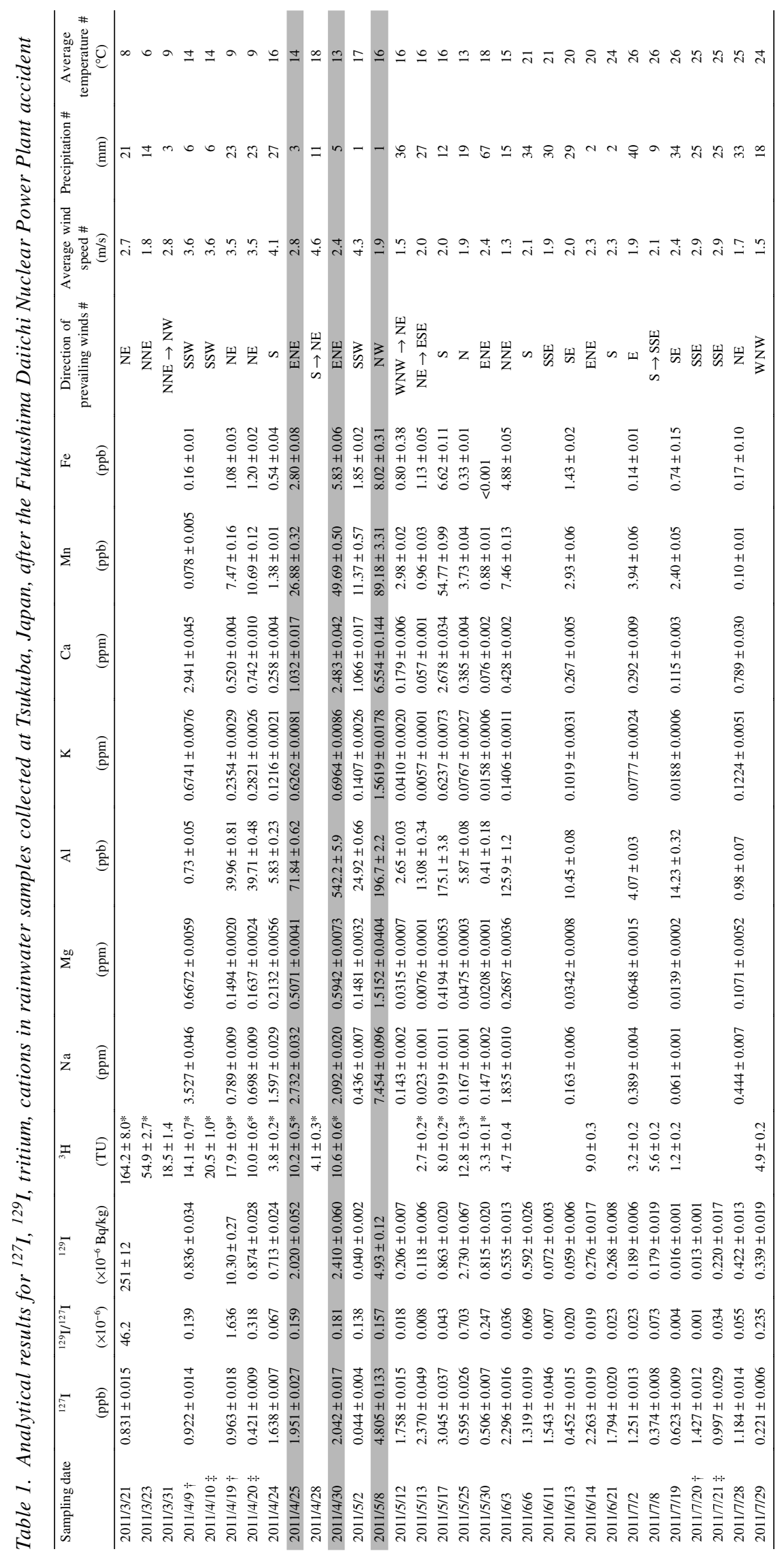




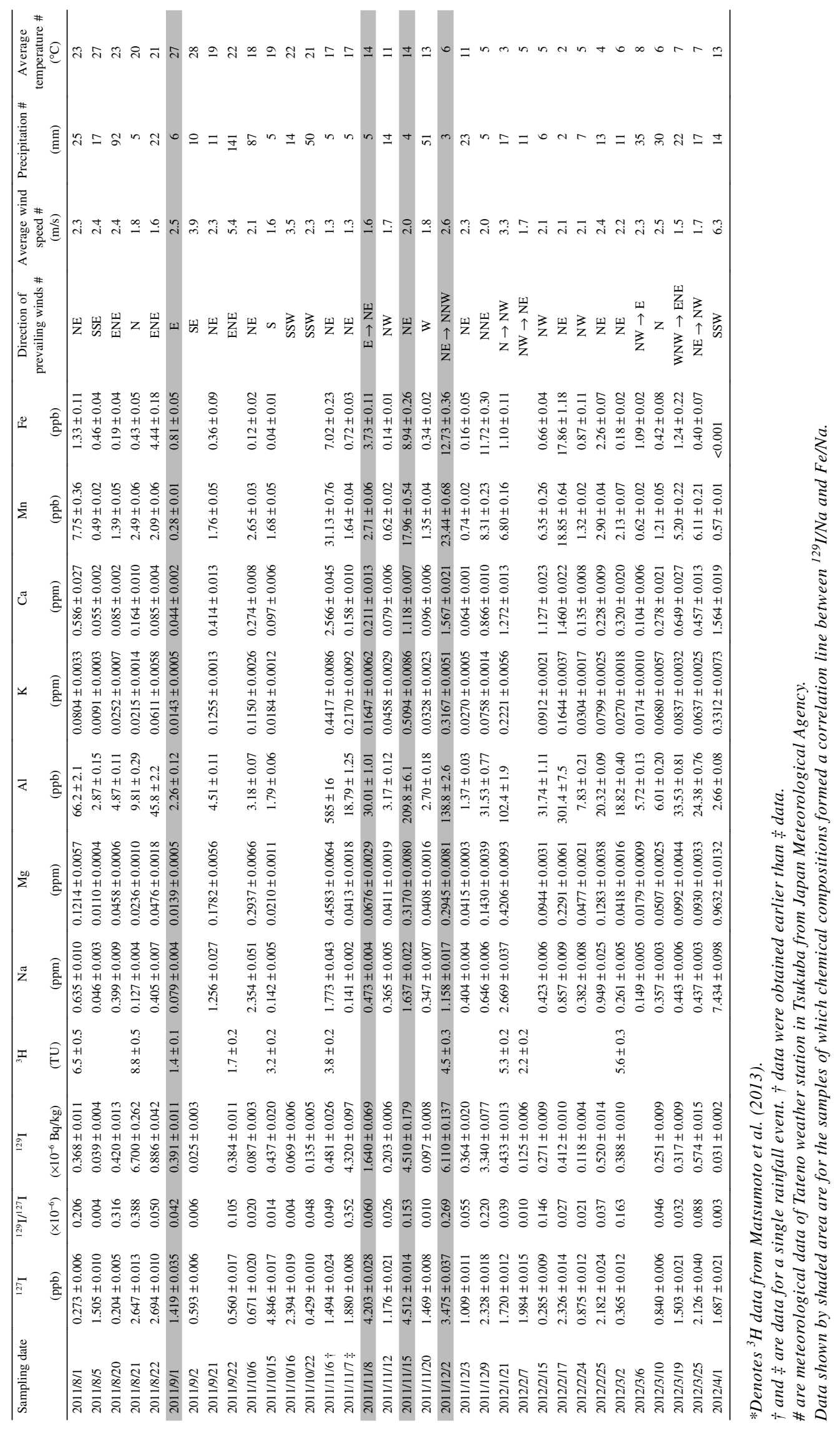




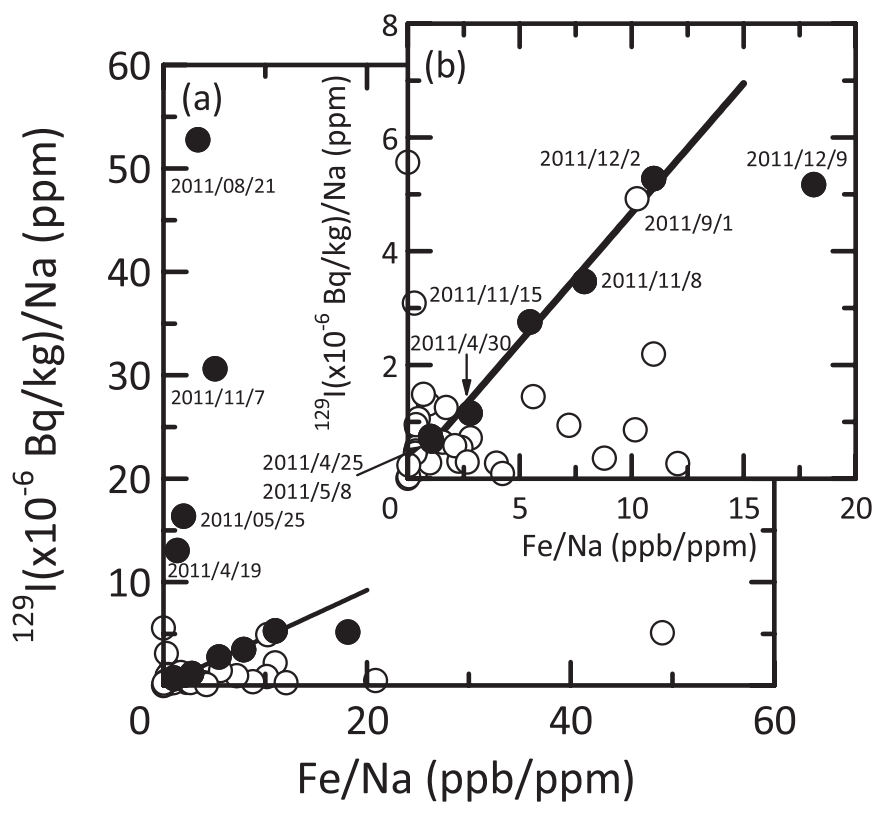

Fig. 5. ${ }^{129} \mathrm{I} / \mathrm{Na}$ ratios plotted against Fe/Na ratios. Closed and open circles represent the data for samples with high $\left(>10^{-6} \mathrm{~Bq} /\right.$ $\mathrm{kg})$ and low $\left(<10^{-6} \mathrm{~Bq} / \mathrm{kg}\right){ }^{129}$ I concentrations, respectively. Solid line represent the regressions line determined from 6 data points for samples with high ${ }^{129}$ I concentrations $\left(R^{2}=0.99\right)$. Numbers near data points indicate sampling dates.

the accident; however, several pulses of high ${ }^{129} \mathrm{I}$ concentrations were observed $\left(>10^{-6} \mathrm{~Bq} / \mathrm{kg}\right.$ : more than two orders of magnitude higher than the minimum concentration for the year) (Fig. 2b). (This threshold value $\left(10^{-6}\right.$ $\mathrm{Bq} / \mathrm{kg}$ ) was arbitrarily set to distinguish high and low concentrations of ${ }^{129} \mathrm{I}$.) This means that ${ }^{129} \mathrm{I}$ entered the atmosphere not only at the time of the accident, but also at several times after the accident, even though no evidence of continuous release of radiogenic volatile substances from the reactor was observed. Similar pulses in the concentration of ${ }^{129} \mathrm{I}$ in rainwater collected at Fukushima were reported by Xu et al. (2013). Except for these pulses of ${ }^{129} \mathrm{I}$, the ${ }^{129} \mathrm{I}$ concentrations show a general correlation with those of ${ }^{3} \mathrm{H}$ (Fig. 3); indicating that ${ }^{129}$ I derived from the FNPP1 accident was washed out of the atmosphere by precipitation, as in the case of ${ }^{3} \mathrm{H}$.

The composition of cations in the rainwater samples can be explained by mixing at least three end-members (Fig. 4): component A (sea salt), component B (higher $\mathrm{Al} / \mathrm{Na}, \mathrm{Ca} / \mathrm{Na}$, and $\mathrm{Mg} / \mathrm{Na}$ ratios than component $\mathrm{A}$ ), and component $\mathrm{C}$ (higher $\mathrm{Al} / \mathrm{Na}$ ratios than component $\mathrm{B}$ ). In Fig. 4, the end-member compositions of components B and $\mathrm{C}$ represent data for precipitation on May 17 and May 13, 2011, respectively. The data points fall along a single line in the $\mathrm{Ca} / \mathrm{Na}$ vs. $\mathrm{Mg} / \mathrm{Na}$ (Fig. $4 \mathrm{a}$ ), $\mathrm{K} / \mathrm{Na}$ vs. $\mathrm{Mg} / \mathrm{Na}$ (Fig. 4b), and $\mathrm{Mn} / \mathrm{Na}$ vs. $\mathrm{Mg} / \mathrm{Na}$ (Fig. 4c) diagrams, because the mixing lines connecting component $\mathrm{A}$ with components $\mathrm{B}$ and $\mathrm{C}$ are colinear in these diagrams. On the other hand, these three end-members are well resolved in the Al/Na vs. Ca/Na (Fig. 4d), Al/Na vs. Mg/Na (Fig. 4e), and $\mathrm{Fe} / \mathrm{Na}$ vs. $\mathrm{Mg} / \mathrm{Na}$ (Fig. 4f) diagrams. In Fig. 4, most data points are located around the point that represents the chemical composition of sea salt, while the data points of the rainwater samples with a high concentration of ${ }^{129} \mathrm{I}$ deviated from the cluster of the sea-salt component. Apparently, the sea salt component has only a very limited influence on the chemical compositions of these high ${ }^{129} I$ samples.

The correlation between ${ }^{129} \mathrm{I} / \mathrm{Na}$ and $\mathrm{Fe} / \mathrm{Na}$ ratios was observed for some (not all) of the data for the samples with high concentrations of ${ }^{129} \mathrm{I}$ (bold line in Fig. 5). The data point for the rainfall of September 1, 2011, was also located on the regression line, although its ${ }^{129} \mathrm{I}$ concentration $\left(3.91 \times 10^{-7} \mathrm{~Bq} / \mathrm{kg}\right)$ is slightly lower than the threshold concentration in this study (i.e., $10^{-6} \mathrm{~Bq} / \mathrm{kg}$ ). It should be noted that a correlation is not expected for the combination of ${ }^{129} \mathrm{I} / \mathrm{Na}$ and other elements. Moreover, although one of the three proposed end-members (component $\mathrm{C}$ ) has a higher $\mathrm{Fe} / \mathrm{Na}$ ratio than the other two components (A and B) (Fig. 4f), the chemical composition for samples forming the ${ }^{129} \mathrm{I} / \mathrm{Na}-\mathrm{Fe} / \mathrm{Na}$ correlation cannot be explained by a mixture of the Fe-enriched component (C) and others (Fig. 4). Therefore, the additional component supplying iron and ${ }^{129} \mathrm{I}$ is supposed to be independent of the three proposed end-members (A, B, and C).

The "pulse" concentrations of ${ }^{129} \mathrm{I}$ in precipitation were likely related to the dissolution of iron oxide (hematite and/or goethite), which can strongly absorb the iodate ion $\left(\mathrm{IO}_{3}^{-}\right)$(Couture and Seitz, 1983). Although possible io- 
dine species in soils are iodide $\left(\mathrm{I}^{-}\right)$, iodate, and organic iodine (e.g., Yamada et al., 1999), the iodide fraction was the major chemical species of ${ }^{129} \mathrm{I}$ in aerosols collected at Tsukuba (Xu et al., 2015). However, such an iodide component cannot directly produce the observed Fe- ${ }^{129} \mathrm{I}$ correlation because iodide ions are not strongly adsorbed by iron oxide (Couture and Seitz, 1983; Kaplan et al., 1999, 2000). Therefore, ${ }^{129}$ I was likely to be provided (at least partially) as iodate ion from iron oxide. As some types of soils are enriched in iron oxide, the ${ }^{129}$ I pulses are likely to have been induced by the dissolution of iron oxide in soils. Except for the rainfall of May 8, 2011, the prevailing winds were between East and North East during collection of the samples that had the ${ }^{129} \mathrm{I} / \mathrm{Na}-\mathrm{Fe} / \mathrm{Na}$ correlation (Table 1). Therefore, ${ }^{129} \mathrm{I}$-bearing iron oxide was likely to have been supplied from an East to North Easterly direction.

\section{Conclusions}

This study analyzed ${ }^{3} \mathrm{H}$ and ${ }^{129} \mathrm{I}$ concentrations in rainfall at Tsukuba, Japan. Although the concentrations of both the radioactive substrates decreased steadily with time and returned to pre-accident levels, several pulses of high ${ }^{129}$ I concentration were also observed. Such high concentrations of ${ }^{129}$ I coincided with high concentrations of iron. Because iron oxides readily absorb iodate ions $\left(\mathrm{IO}_{3}{ }^{-}\right)$and are generally rich in soils, at least part of ${ }^{129} \mathrm{I}$ in precipitation was likely incorporated into rainwaters by dissolution of iron oxide in soils and could be transported even after other species of ${ }^{129} \mathrm{I}$ were exhausted from the atmosphere.

Acknowledgments-We would like to thank Nur Ozyurt, George Burr and an anonymous reviewer for their constructive reviews and suggestions. This work is partly supported by the IAEA research agreement, JPN16797, and by a Grant-in-Aid program of the Japan Society for the Promotion of Science (Grant No. 24101010).

\section{REFERENCES}

Couture, R. A. and Seitz, M. G. (1983) Sorption of anions of iodine by iron oxides and kaolinite. Nucl. Chem. Waste Man. 4, 301-306.

Doi, T., Masumoto, K., Toyoda, A., Tanaka, A., Shibata, Y. and Hirose, K (2013) Anthropogenic radionuclides in the atmosphere observed at Tsukuba: characteristics of the radionuclides derived from Fukushima. J. Environm. Radioact. 122, 55-62.

Gröning, M., Auer, R., Brummer, D., Jaklitsch, M., Sambandam, C., Tanweer, A. and Tatzber, H. (2009) Increasing the performance of tritium analysis by electrolytic enrichment. Isotopes Environ. Health Stud. 45, 118-125.

Hirose, K. (2012) 2011 Fukushima Dai-ichi Nuclear Power Plant accident: summary of regional radioactive deposition moni- toring results. J. Environm. Radioact. 111, 13-17.

Kaplan, D. I., Serne, R. J., Parker, K. E. and Kutnyakov, I. V. (1999) Radioiodide sorption to sediment minerals. Mat. Res. Soc. Symp. Proc. 556, 1059-1065.

Kaplan, D. I., Serne, R. J., Parker, K. E. and Kutnyakov, I. V. (2000) Iodide sorption to subsurface sediments and illitic minerals. Environ. Sci. Technol. 34, 399-405.

Khazov, Yu., Mitropolsky, I. and Rodionov, A. (2006) Nuclear data sheets for A = 131. Nuclear Data Sheets 107, 27152930.

Lucas, L. L. and Unterweger, M. P. (2000) Comprehensive review and critical evaluation of the half-life of tritium. $J$. Res. Natl. Inst. Stand. Technol. 105, 541-549.

Matsumoto, T., Maruoka, T., Shimoda, G., Obata, H., Kagi, H., Suzuki, K, Yamamoto, K., Mitsuguchi, T., Hagino, K., Tomioka, N., Sambandam, C., Brummer, D., Klaus, P. M. and Aggarwal, P. (2013) Tritium in Japanese precipitation following the March 2011 Fukushima Daiichi Nuclear Plant accident. Sci. Total Environ. 445, 365-370.

Matsuzaki, H., Muramatsu, Y., Kato, K., Yasumoto, M. and Nakano, C. (2007) Development of ${ }^{129}$ I-AMS system at MALT and measurements of ${ }^{129} \mathrm{I}$ concentrations in several Japanese soils. Nucl. Instrum. Meth. B 259, 721-726.

Miyake, Y., Matsuzaki, H., Fujiwara, T., Saito, T., Yamagata, T., Honda, M. and Muramatsu, Y. (2012) Isotopic ratio of radioactive iodine $\left({ }^{129} \mathrm{I} /{ }^{131} \mathrm{I}\right)$ released from Fukushima Daiichi NPP accident. Geochem. J. 46, 327-333.

Muramatsu, Y., Matsuzaki, H., Toyama, C. and Ohno, T. (2015) Analysis of ${ }^{129} \mathrm{I}$ in the soils of Fukushima Prefecture: Preliminary reconstruction of ${ }^{131}$ I deposition related to the accident at Fukushima Daiichi nuclear power plant. $J$. Environm. Radioact. 139, 344-350.

Schwantes, J. M., Orton, C. R. and Clark, R. A. (2012) Analysis of a nuclear accident: fission and activation product releases from the Fukushima Daiichi nuclear facility as remote indicators of source identification, extent of release, and state of damaged spent nuclear fuel. Environ. Sci. Technol. 46, 8621-8627.

Steinhauser, G. (2014) Fukushima's forgotten radionuclides: A review of the understudied radioactive emissions. Environ. Sci. Technol. 48, 4649-4663

Timar, J., Elekes, Z. and Singh, B. (2014) Nuclear data sheets for $\mathrm{A}=129$. Nuclear Data Sheets 121, 143-394.

Xu, S., Freeman, S. P. H. T., Hou, X., Watanabe, A., Yamaguchi, K. and Zhang, L. (2013) Iodine isotopes in precipitation: Temporal responses to ${ }^{129} \mathrm{I}$ emissions from the Fukushima nuclear accident. Environ. Sci. Technol. 47, 10851-10859.

Xu, S., Zhang, L., Freeman, S. P., Hou, X., Shibata, Y., Sanderson, D., Cresswell, A., Doi, T. and Tanaka, A. (2015) Speciation of radiocesium and radioiodine in aerosols from Tsukuba after the Fukushima nuclear accident. Environ. Sci. Technol. 49, 1017-1024.

Yabusaki, S., Tsujimura, M. and Tase, N. (2003) Recent trend of tritium concentration in precipitation in Kanto Plain, Japan. Bull. Terr. Environ. Res. Cent. 4, 119-124.

Yamada, H., Kiriyama, T., Onagawa, Y., Hisamori, I., Miyazaki, C. and Yonebayashi, K. (1999) Speciation of iodine in soils. Soil Sci. Plant Nutr. 45, 563-568. 